Journal of Advanced Research in Fluid Mechanics and Thermal Sciences

\title{
Pulsed Nd: YAG Laser Parameters Effect on Welding Uncoated Advance High Strength Steel (AHSS) for Automotive
}

\author{
Muhammad Naqiuddin Mat Salleh ${ }^{1,}{ }^{*}$, Mahadzir Ishak ${ }^{1}$, Kazuhiko Yamasaki ${ }^{2}$, Moinuddin \\ Mohammed Quazi ${ }^{1}$, Aiman Mohd Halil ${ }^{1}$ \\ 1 Joining, Welding, and Laser Processing Lab (JWL), Faculty of Mechanical and Automotive Engineering Technology, Universiti Malaysia Pahang, \\ 26600 Pekan, Pahang, Malaysia \\ 2 Graduate School of Science and Engineering, Department of Mechanical Engineering, Ibaraki University, 4-12-1 Nakanarusawa, Hitachi City, \\ Ibaraki, 316-8511, Japan
}

\section{ARTICLE INFO}

\section{Article history:}

Received 25 December 2020

Received in revised form 10 May 2021

Accepted 15 May 2021

Available online 1 July 2021

\section{Keywords:}

Low power laser; pulse wave mode; parameter effects

\section{ABSTRACT}

\begin{abstract}
Pulse wave (PW) welding technique has become a more adequate process to produce a deep penetration welding with smaller fusion zone and heat affected zone (HAZ) for automotive steel joint. A $1.6 \mathrm{~mm}$ thickness of N22CB boron steel from advance high strength steel (AHSS) type was welded by using PW mode from a low power Nd: YAG laser. The process parameters studied in this paper were pulsed energy, $E_{p}$, foca length, $F$, and welding speed, $S$. Bead-on-plate (BOP) welding was used in this experiment. The effect of parameters on the weld pool geometry was studied. Higher pulsed energy gave high weld penetration and higher weld width, contributing to the bigger weld pool size. The positive defocus position of focal length produced weld geometry with high penetration depth and smaller bead width compared to the negative defocus position. Lower welding speed was capable to produce deep penetration depth as the high heat input produced.
\end{abstract}

\section{Introduction}

Laser welding has proved itself to be a versatile tool of power since it has been introduced since 1970 [1]. Until 2018, the laser welding method gained great popularity as it has advantages of joining technology with high quality, high precision, high performance, high speed, better flexibility, low distortion defect, and ease of use with full automation access [2]. Laser welding is known as a fusion welding process in which two different or similar metals are joined together by a concentrated heat source produced from the laser beam light which gives a high power density of energy to concentrate heat at a small area [3]. The application of laser welding in many industries also increasing throughout the years.

In laser welding application, there were two ways processes, which is by using continuous wave (CW) mode and pulse wave (PW) mode. Usually, the CW mode technique needs high power laser to

\footnotetext{
* Corresponding author.

E-mail address: mdnaqiuddinsalleh91@gmail.com
}

https://doi.org/10.37934/arfmts.84.1.91100 
achieve high weld penetration depth since the average power of the laser was used directly as the processing power during the welding process [4]. Meanwhile, PW mode can increase the peak power of the laser even using low power laser to achieve high penetration depth with the setup of PW parameters such as pulse frequency, pulse duration, duty cycles, etc [5]. The study of parameters effects in all welding and joining process was very important since it affects the performance of the welded part itself [6].

At laser high peak power by using just a low power laser machine, deep penetration welding and defects free joint results can be achieved [7]. In addition to that, this PW mode technique could be applied by industry such as automotive sectors, where the cost could be minimized by installation low power laser. Automotive steel nowadays always upgrading to newer materials, where it comes to the high strength and minimizing the weight requirement following the needs of global energy transformation towards 2050 [8]. Advance high strength steel (AHSS) has established itself as a material that comply with the needs of the automotive industry, which is continually adapting highly stringent requirements on vehicle safety, reduction in vehicle mass, and strength increment after been hot stamped process [9].

The application of laser welding was practically used in joining the AHSS for these recent years such as Dual-phase (DP) steel, transformation-induced plasticity (TRIP) steel, boron steel, etc [10-12]. The application of PW mode to weld AHSS is truly needed to produce deep penetration weld with free defects, resulting in high strength joining product. AHSS materials usually adapted to the structure of the vehicle where the need for a strong structure was required. The present article shows, discusses, and categorizes the results of the weld geometry for the effect of the variation of PW mode process parameters during BOP welding processes. The aim of this paper is to investigate the effect of PW mode process parameters on weld pool geometry of BOP welded Boron steel. Furthermore, a method was developed to present and collect the results in an easier way to understand the effect of process parameters on the weld joint geometry.

\section{Methodology}

The Material used in this experiment was uncoated N22CB boron steel with a dimension of $100 \mathrm{x}$ $100 \times 1.8 \mathrm{~mm}$ thickness. Bead on plate (BOP) welding was applied in this experiment. The samples were cleaned with ethanol before the welding process was carried out. In this experimental work, an $\mathrm{Nd}$ : YAG laser machine with the maximum average power of 300 Watt was used with a $1064 \mathrm{~nm}$ wavelength. The focus beam diameter used for this machine was 0.2 to $0.3 \mathrm{~mm}$. Pulse wave mode was applied in this experiment, where the significant laser parameters were varied through the process. The workpiece was placed at the jig, where the table was moved for the welding line and the head movement was fixed at the focus point position. The schematic illustration of the laser welding setup was shown in Figure 1.

Figure 1(a) shows the front view of the laser setup for BOP welding. The specimen was placed at the jig base and clamped to avoid distortion during the welding process. Argon gas was used as shielding gas for this experiment. Figure $1(\mathrm{~b})$ shows the illustration of the laser seam line at the parent metal where the pulsed laser beam was applied to the sample. After the welding process was done, the BOP welded sample was cut at the cross-section region for further weld geometrical observation as depicted in Figure 1(c). 
All samples were then mounted using a hot mounting process and prepared for metallurgy sample preparations. Samples were ground using 180, 240, 320, 480, and 600 grit of sandpaper, and then were polished using 9 and $3 \mu \mathrm{m}$ diamond extender and $0.5 \mu \mathrm{m}$ of colloidal silica for mirror surface finish. For macrostructure reveal, the mixture of $10 \mathrm{ml}$ of $30 \%$ Nitric acid with $15 \mathrm{ml}$ of distilled water was used as the etchant solution. Figure 2 shows the schematic illustration of weld geometry analysis of the BOP weld at the cross-sectional area of stable welding region.
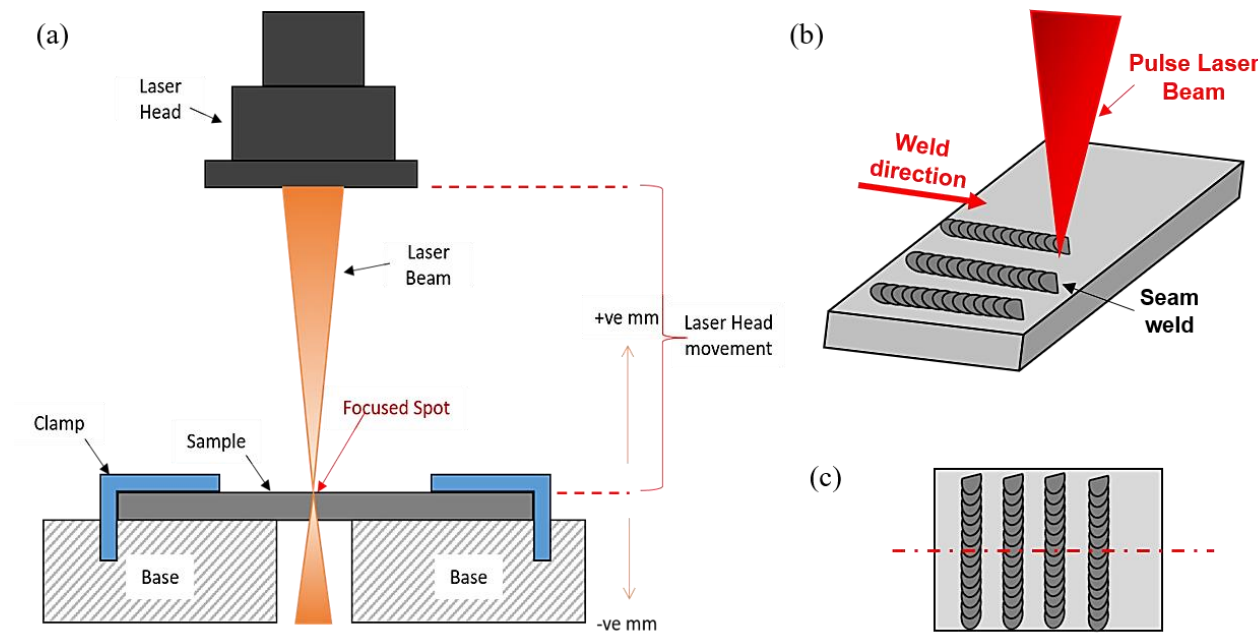

Fig. 1. Schematic Illustration of (a) front view of laser welding setup, (b) 3D view of laser BOP welding, and (c) cross sectional cutting line of the BOP weld

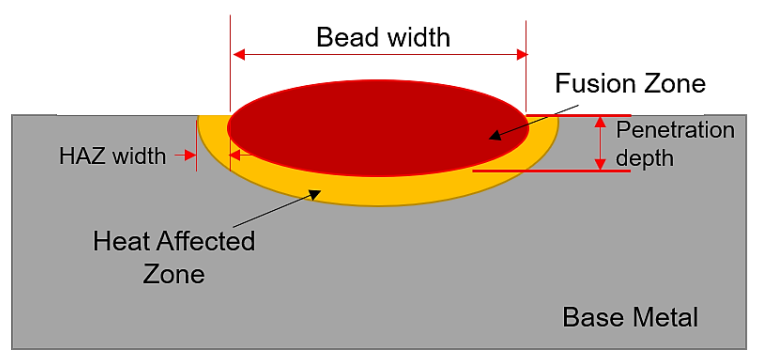

Fig. 2. Schematic illustration of weld geometrical analysis

The optical microscope was used to capture the images of the weld pool geometry. The crucial parameters that affect the weld geometry of $\mathrm{N} 22 \mathrm{CB}$ boron steel samples used in this experiment were pulsed energy, $E_{p}$, focal length, $F$, and Welding speed, $S$.

\subsection{Variant Pulsed Energy, $E_{p}$}

The pulse energy (Joules) parameters are shown in Table 1. To get the pulse energy value, the other pulse wave modes of Nd: YAG laser parameters, such as voltage, pulse frequency, and pulse width need to be set accordingly. The constant parameters used in this experiment are welding speed $(\mathrm{S})$ at $50 \mathrm{~mm} / \mathrm{min}$, focal length (F) at focus point (defocus at $0 \mathrm{~mm}$ ), argon shielding gas at $10 \mathrm{~L} / \mathrm{min}$. 


\section{Table 1}

Parameters setup for variant pulsed energy

\begin{tabular}{lllll}
\hline Sample & Voltage, $(\mathrm{V})$ & Pulse Frequency, $(\mathrm{Hz})$ & Pulse width, $(\mathrm{ms})$ & Pulse energy, $E_{p}(\mathrm{~J})$ \\
\hline 1 & 250 & 80 & 2.5 & 1.56 \\
2 & 220 & 20 & 10.0 & 3.62 \\
3 & 230 & 20 & 10.0 & 5.08 \\
4 & 240 & 20 & 10.0 & 6.65 \\
5 & 250 & 20 & 10.0 & 8.50 \\
6 & 260 & 20 & 10.0 & 10.4 \\
7 & 310 & 20 & 10.0 & 12.7 \\
8 & 310 & 15 & 6.5 & 13.4 \\
9 & 310 & 15 & 7.0 & 14.6 \\
\hline
\end{tabular}

\subsection{Variant Focal Length, $F$}

For this experiment, only one fixed laser parameters were chosen, which is; $310 \mathrm{~V}, 15 \mathrm{~Hz}, 7 \mathrm{~ms}$ (at 14.6 Joules of $\left.E_{p}\right), 50 \mathrm{~mm} / \mathrm{min}$ of $\mathrm{S}$, and $10 \mathrm{~L} / \mathrm{min}$ of $\mathrm{Ar}$ shielding gas. The focal position was varied from negative defocused to positive defocused. Table 2 shows the parameters set up for variant focal length position setup.

\begin{tabular}{l} 
Table 2 \\
\multicolumn{4}{l}{ Parameters setup for variant focal length } \\
\begin{tabular}{lll}
\multicolumn{4}{l}{ Sample } & Focal Position, $F(\mathrm{~mm})$ & Fixed parameters \\
\hline 10 & -2 & \\
11 & -1 & $E p=14.6 \mathrm{~J}$ \\
12 & 0 & $S=50 \mathrm{~mm} / \mathrm{min}$ \\
13 & +1 & $\mathrm{Ar}=10 \mathrm{~L} / \mathrm{min}$ \\
14 & +2 & \\
\hline
\end{tabular}
\end{tabular}

\subsection{Variant Welding Speed, $S$}

For this experiment, selected laser parameters were; $310 \mathrm{~V}, 15 \mathrm{~Hz}, 7 \mathrm{~ms}$ (at $14.6 \mathrm{Joules}$ of $E_{p}$ ), and $+2 \mathrm{~mm}$ of the focal position. Scanning speed used were; $100 \%$ (50 mm/min), $80 \%$ (40 mm/min), $60 \%$ (30 mm/min), and 40\% (20 mm/min). Table 3 shows the parameters set up for this experiment.

Table 3

\begin{tabular}{lll}
\multicolumn{3}{l}{ Parameters setup for variant welding speed } \\
\hline Sample & Weld speed, $S(\mathrm{~mm} / \mathrm{min})$ & Fixed parameters \\
\hline 15 & 20 & $E p=14.6 \mathrm{~J}$ \\
16 & 30 & $F=+2 \mathrm{~mm}$ \\
17 & 40 & $\mathrm{Ar}=10 \mathrm{~L} / \mathrm{min}$ \\
18 & 50 & \\
\hline
\end{tabular}

\section{Results}

\subsection{The Effect of Pulsed Energy, $E_{p}$}

The macrograph of the cross-sectional area for this experiment is shown in Figure 3. From this figure, it was observed that the pulsed energy from 1.56 until $10.4 \mathrm{~J}$ (sample 1 to sample 6) created shallow weld penetration, compared to the results from sample welded with 12.7 to $14.6 \mathrm{~J}$ (sample 7 to sample 9). However, underfill defects presented at samples welded with 12.7 to $14.6 \mathrm{~J}$. The weld width and penetration depth were measured, and the data were tabulated in Table 4. 
From Table 4, it was observed that sample number 9, which possessed pulsed energy of $14.6 \mathrm{~J}$ produced the highest penetration depth, $0.58 \mathrm{~mm}$. The lowest weld penetration was produced by sample welded with $3.62 \mathrm{~J}$ of pulsed energy with the $0.64 \mathrm{~mm}$ of bead width size. For a clear observation of the effect of pulsed energy on the N22CB boron steel, the graph of the relationship between pulsed energy and weld penetration and bead width was constructed based on the results as shown in Figure 4.
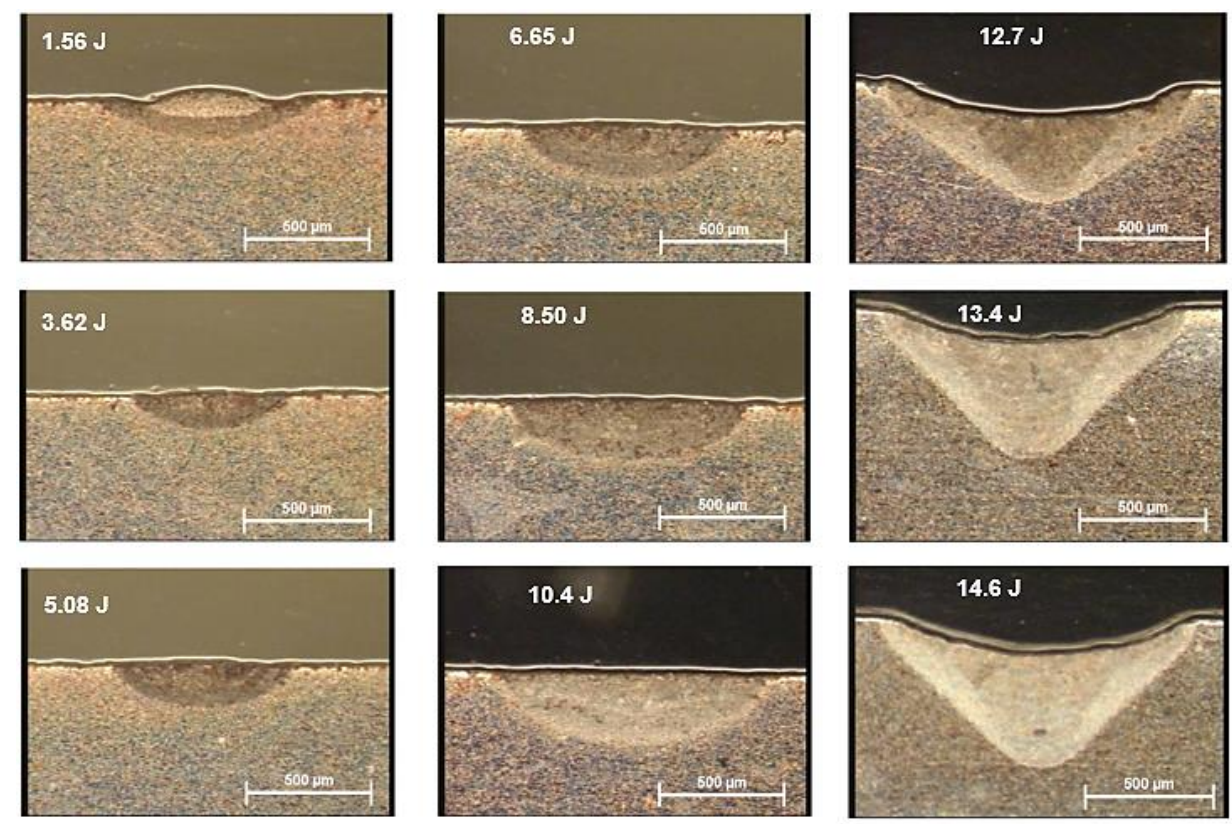

Fig. 3. Effect of variant pulsed energy on the weld pool geometry

Table 4

Results for variant pulsed energy experiment

\begin{tabular}{llll}
\hline Sample & Pulse energy, $\mathrm{E}(\mathrm{J})$ & Bead width, $\mathrm{mm}$ & Penetration depth, $\mathrm{mm}$ \\
\hline 1 & 1.56 & 0.42 & 0.15 \\
2 & 3.62 & 0.64 & 0.12 \\
3 & 5.08 & 0.72 & 0.17 \\
4 & 6.65 & 0.83 & 0.22 \\
5 & 8.50 & 0.97 & 0.24 \\
6 & 10.4 & 1.14 & 0.29 \\
7 & 12.7 & 1.23 & 0.46 \\
8 & 13.4 & 1.26 & 0.58 \\
9 & 14.6 & 1.28 & 0.58 \\
\hline
\end{tabular}

The bead width size and weld penetration depth show an increasing trend as the pulsed energy increased (as depicted in Figure 4). Highest weld penetration produced at the highest energy (14.6 $\mathrm{J})$, which is $0.58 \mathrm{~mm}$. In addition to that, the weld depth produced was not sufficient to produce a butt weld joint for a $1.6 \mathrm{~mm}$ thick of $\mathrm{N} 22 \mathrm{CB}$. As observed from this experiment, pulsed energy plays an important in producing a deeper weld penetration. Higher pulsed energy creates higher heat input at a constant welding speed for a weld, which is increasing the weld pool size [13]. The bead width and penetration depth increase as the pulse energy increases. 


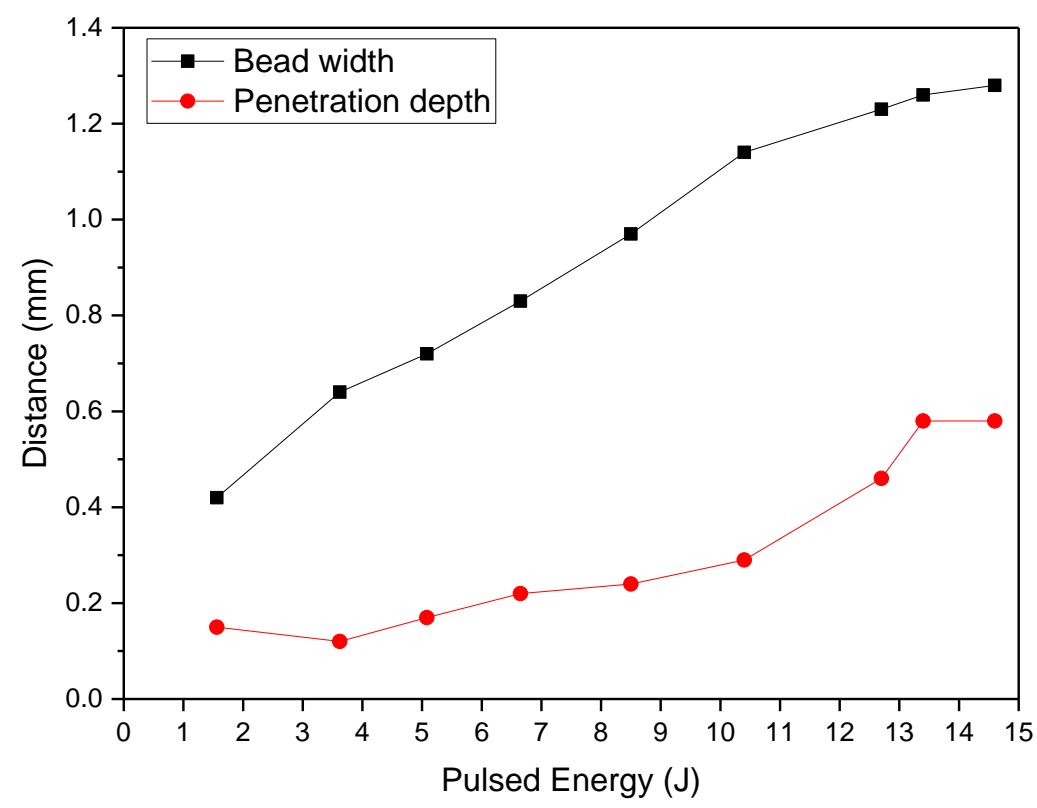

Fig. 4. Effect of pulsed energy changes on weld pool geometry

\subsection{The Effect of Focal Length, $F$}

The macrograph images of the weld pool geometry for different focal length are shown in Figure 5. Five samples produced at five different focal positions to observe its effect on the weld geometry.
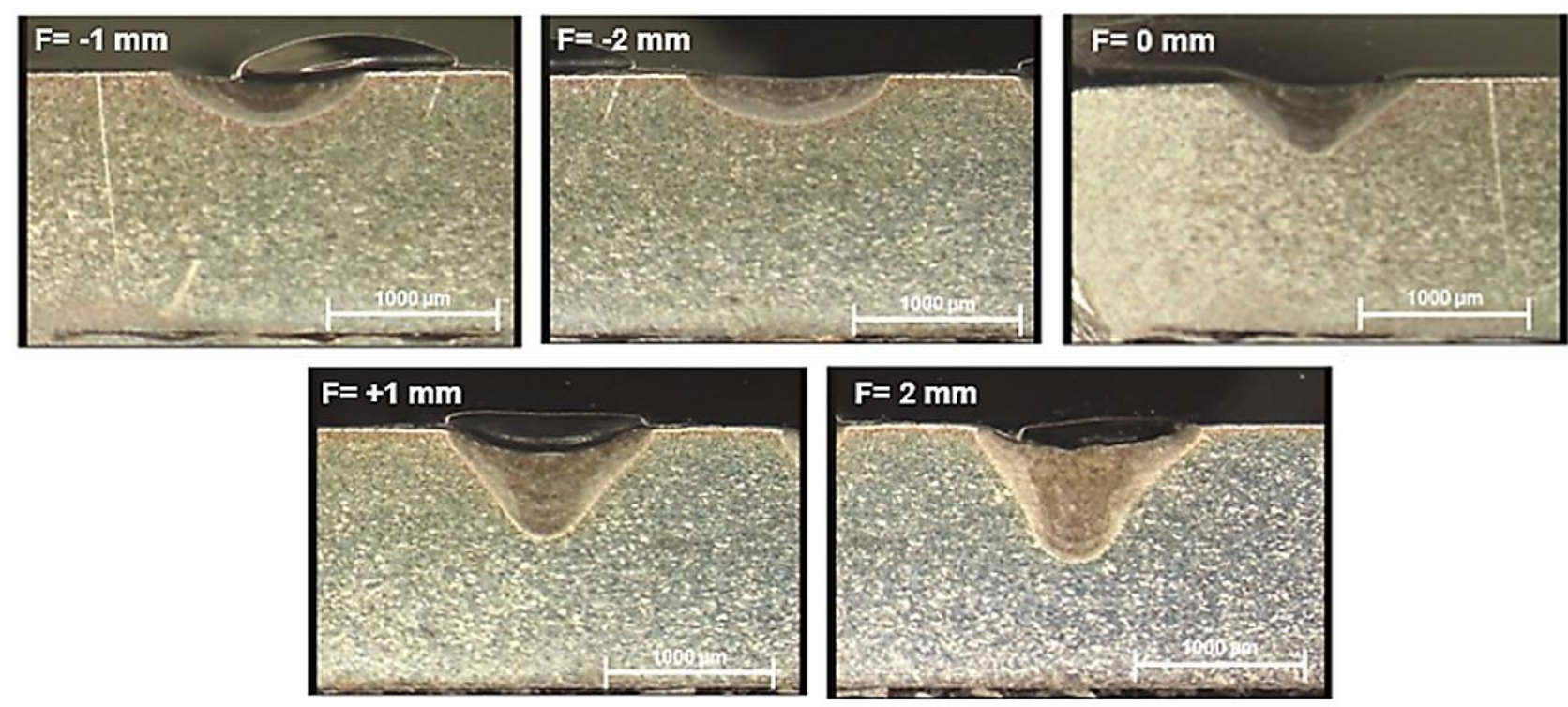

Fig. 5. Effect of defocusing position on weld pool geometry

From Figure 5, it was observed that negative defocus of the focal length produced less penetration at $14.6 \mathrm{~J}$ of pulse energy used. The shape of the weld pool indicates the conduction weld where shallow penetration with a wider bead width distance produced [14]. The weld width and penetration depth measurements were collected in Table 5. From this table, it was observed that the bead width was large at negative defocus position, which is at $1.61 \mathrm{~mm}$ and the width is reduced at the focus position, which is at $1.21 \mathrm{~mm}$. 


\section{Table 5}

Results for variant defocus position experiment

\begin{tabular}{llll}
\hline Sample & Defocus $(\mathrm{mm})$ & Bead width, $(\mathrm{mm})$ & Penetration depth, $(\mathrm{mm})$ \\
\hline 10 & -2 & 1.61 & 0.29 \\
11 & -1 & 1.61 & 0.28 \\
12 & 0 & 1.21 & 0.4 \\
13 & +1 & 1.234 & 0.65 \\
14 & +2 & 1.355 & 0.82 \\
\hline
\end{tabular}

When entering the positive defocus region, the bead width was slightly increased again compared to the negative defocus with an increment of 0.02 to $0.145 \mathrm{~mm}$. The penetration depth keeps increasing from 0.29 to $0.82 \mathrm{~mm}$ as the laser focal length increased from the negative to positive defocus position. The smallest bead width was recorded at the focus point section. The graph of weld width and penetration depth against the defocus position of the laser beam is presented in Figure 6 .

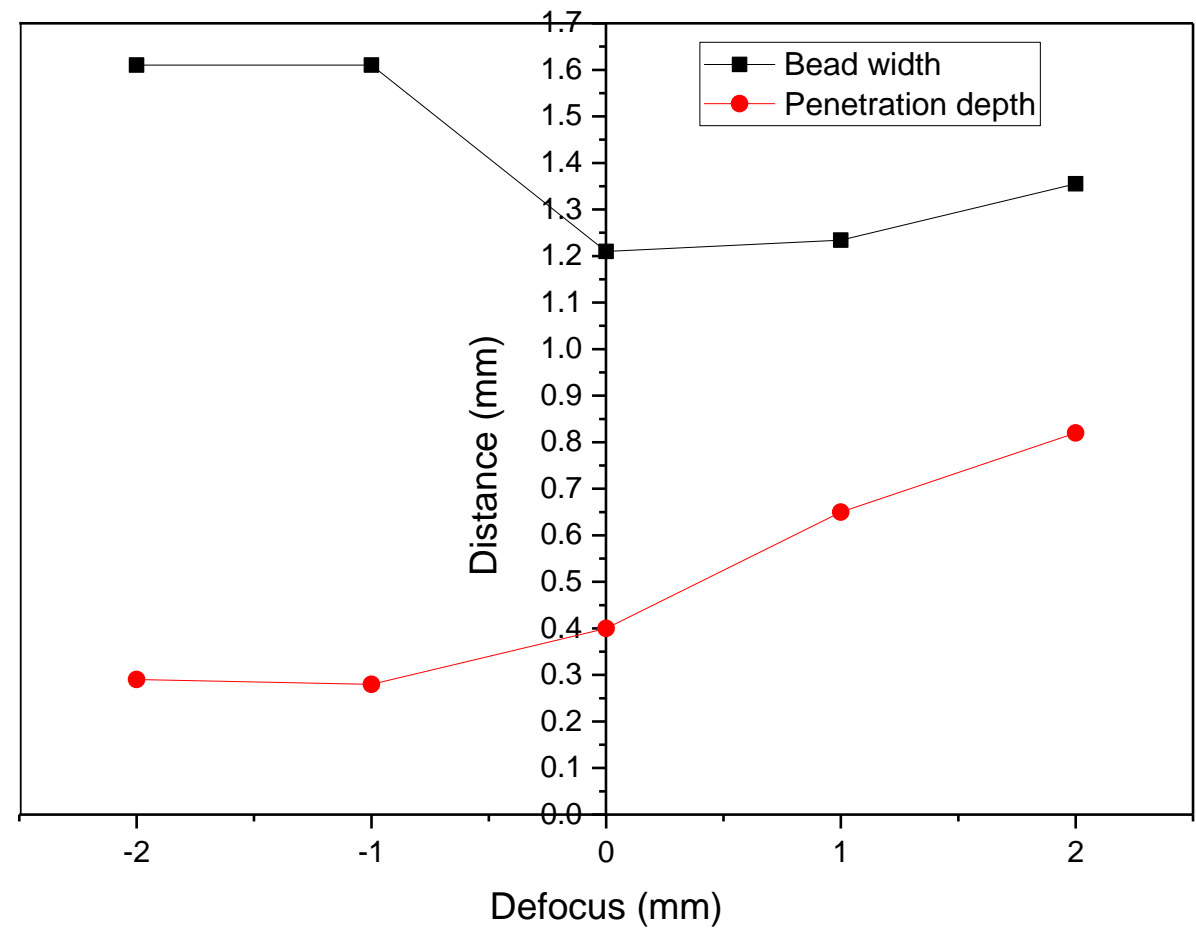

Fig. 6. Effect of defocus position on weld pool size geometry

From Figure 6, it was depicted the increasing trends of weld penetration depth as the defocus position entering the positive defocus region from the focus point (defocus position at $0 \mathrm{~mm}$ ). At the negative defocus region, the weld depth was found to be approximately similar depth. It was found also that the negative defocus position produces the same size of weld width. The weld width became smaller as the focal length was positioned at the focus point.

A slight increment was observed as the defocus position was in the positive region. For a better weld size analysis, smaller bead width with high penetration depth was considered a better weld characteristic as possessing a lower aspect ratio, where a lower aspect ratio indicating that the weld geometry produced was more toward the keyhole characteristics [12]. The positive defocus position produced a weld pool geometry with high penetration depth and a smaller weld width compared to the negative defocus position. 


\subsection{The Effect of Welding Speed, $\mathrm{S}$}

Welding speed used in this experiment were; $100 \%$ (50 mm/min), $80 \%$ (40 mm/min), 60\% (30 $\mathrm{mm} / \mathrm{min})$, and $40 \%$ (20 mm/min). Figure 7 depicts the macrograph images of welded samples for variant scanning speed at fixed $14.6 \mathrm{~J}$ of $E_{p}$ and $+2 \mathrm{~mm}$ of $F$.

All samples produced underfill defects (as depicted in Figure 7) and higher penetration depth was observed from the macrograph images as the welding speed was slower from 50 to $20 \mathrm{~mm} / \mathrm{min}$. At $40 \mathrm{~mm} / \mathrm{min}$, a hot crack was found at the weld zone region. This is due to the rapid cooling process that occurred in the fusion zone during the laser welding process, which creates surface tension during the solidification of the fusion zone [15].
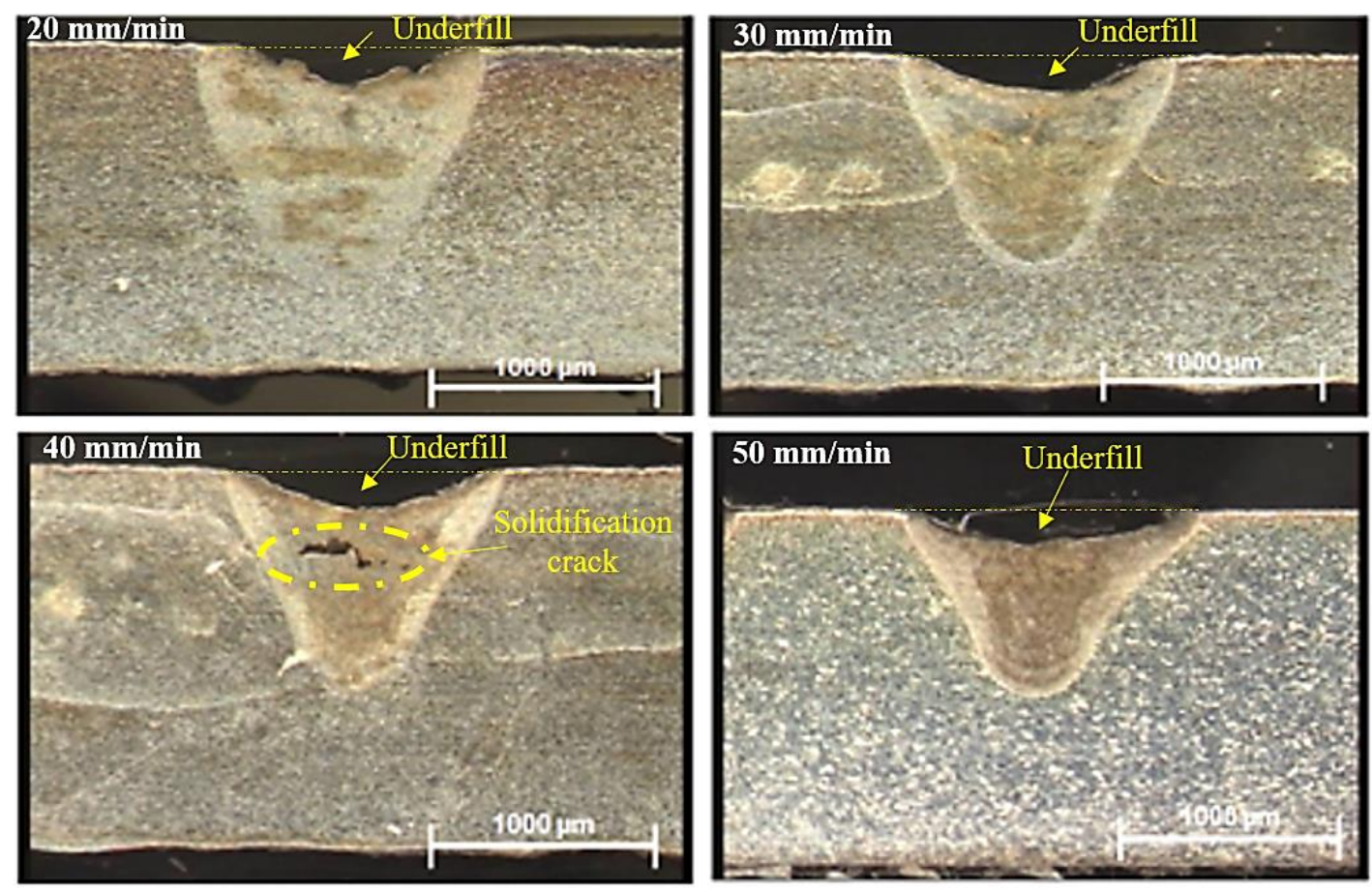

Fig. 7. Effect of welding speed on weld pool geometry

The bead width and penetration depth measurement were collected as shown in Table 6 . From this table, it was shown that the highest penetration depth $(1.2 \mathrm{~mm})$ produced at the utilization of $20 \mathrm{~mm} / \mathrm{min}$ of welding speed. Meanwhile, a faster welding speed at $50 \mathrm{~mm} / \mathrm{min}$ only produced penetration depth at $0.85 \mathrm{~mm}$. For the weld width measurement, there were not many effects as the width distance was approximately similar (1.25 to $1.3 \mathrm{~mm}$ width). The graph of weld width and penetration depth against the welding speed is presented in Figure 8.

Table 6

Results for variant welding speed experiment

\begin{tabular}{llll}
\hline Sample & Weld speed, $\mathrm{mm} / \mathrm{min}$ & Penetration depth, $\mathrm{mm}$ & Bead width, $\mathrm{mm}$ \\
\hline 15 & 20 & 1.20 & 1.25 \\
16 & 30 & 1.01 & 1.24 \\
17 & 40 & 0.98 & 1.28 \\
18 & 50 & 0.85 & 1.30 \\
\hline
\end{tabular}


The weld width was approximately similar size as the welding speed increased as shown in Figure 8. However, the penetration depth has a large difference as the weld depth became shallower as the welding speed increased. The cause of this reason was due to the insufficient heat input absorbed by the parent metal during the welding process as the speed of welding increases [16]. For this variant welding speed experiment, it was found that the penetration depth decreases as the welding speed increases. Meanwhile, there is no large effect on the weld width for variant welding speed parameters.

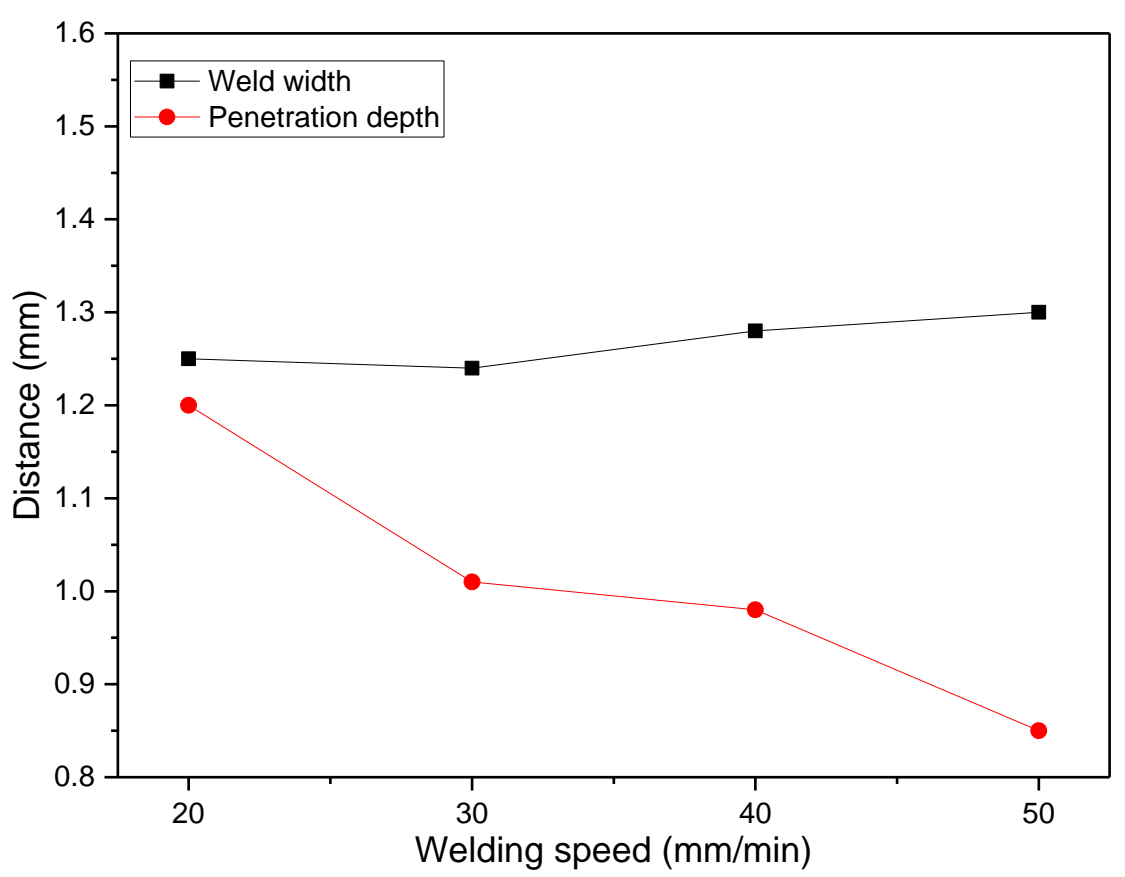

Fig. 8. Effect of different welding speed on weld pool size geometry

\section{Conclusions}

From the finding of the laser welding parameters effect on the AHSS boron steel, the effects of pulsed energy, defocussing features, and welding speed on the weld pool geometry produced with pulse wave (PW) mode of low power Nd: YAG laser were examined. The findings from this paper are summarized as follows

i. $\quad$ The bead width and penetration depth increase as the pulse energy increases.

ii. Positive defocus position produced a weld pool geometry with high penetration depth and a smaller weld width compared to the negative defocus position.

iii. Penetration depth decreases as the welding speed increases and there is no large effect on the weld width for variant welding speed parameters.

iv. For a better high penetration and smaller weld width, higher pulsed energy at positive defocus position and slower welding speed can be applied.

\section{Acknowledgement}

This research was funded by a grant from the Ministry of Higher Education of Malaysia RDU190123 (FRGS/1/2018/TK03/UMP/02/9), a grant from UMP (PGRS1903149), and sponsored by Sakura Science Program by the Japan Science and Technology Agency (JST) through the Department of Mechanical Engineering, Ibaraki University, Hitachi Campus. 


\section{References}

[1] Injeyan, Hagop, and Gregory D. Goodno. High power laser handbook. McGraw-Hill Education, 2011.

[2] Katayama, S. "Understanding and improving process control in pulsed and continuous wave laser welding." In Advances in Laser Materials Processing, pp. 153-183. Woodhead Publishing, 2018. https://doi.org/10.1016/B978-0-08-101252-9.00007-8

[3] Olabi, A. G., R. Lostado, and K. Y. Benyounis. "Review of microstructures, mechanical properties, and residual stresses of ferritic and martensitic stainless-steel welded joints." Comprehensive Materials Processing 6 (2014): 181-192. https://doi.org/10.1016/B978-0-08-096532-1.00617-8

[4] Katayama, Seiji. "Formation mechanisms and preventive procedures of laser welding defects." In Fundamentals and Details of Laser Welding, pp. 87-111. Springer, Singapore, 2020. https://doi.org/10.1007/978-981-15-7933-2 5

[5] Yaakob, K. I., M. Ishak, M. M. Quazi, and M. N. M. Salleh. "Optimizing the pulse wave mode low power fibre laser welding parameters of 22Mnb5 boron steel using response surface methodology." Measurement 135 (2019): $452-$ 466. https://doi.org/10.1016/i.measurement.2018.10.035

[6] Khattak, Muhammad Adil, Shahid Zaman, Mohd Nasir Tamin, Saeed Badshah, Syed Mushtaq, and Abdoulhdi Amhmad Borhana Omran. "Effect of welding phenomenon on the microstructure and mechanical properties of ferritic stainless steel-A review." Journal of Advanced Research in Materials Science 32, no. 1 (2017): 13-31.

[7] Yan, Shi, Zhang Hong, Takehiro Watanabe, and Tang Jingguo. "CW/PW dual-beam YAG laser welding of steel/aluminum alloy sheets." Optics and Lasers in Engineering 48, no. 7-8 (2010): $732-736$. https://doi.org/10.1016/j.optlaseng.2010.03.015

[8] Taylor, Michael. "Energy subsidies: Evolution in the global energy transformation to 2050." International Renewable Energy Agency, Abu Dhabi (2020).

[9] Duran-Nunez, A., A. L. Ramirez-Ledesma, H. Lopez, and J. A. Juarez-Islas. "On the Microstructural and Mechanical Behavior of a Fe-0.3 C-2.3 Mn-0.22 Si-0.5 Cr-0.13 Ti-0.005 B Steel Intended for Automotive Applications." Journal of Materials Engineering and Performance 29, no. 10 (2020): 6513-6519. https://doi.org/10.1007/s11665-02005172-3

[10] Tunçel, O., Aydin, H., and Çetin, Ş. "Microstructure and Mechanical Properties of Similar And Dissimilar Laser Welds of DP600 and DP1000 Steel Sheets Used in The Automotive Industry." Turkish Journal of Engineering 5, no. 1 (2020): 8-15. https://doi.org/10.31127/tuje.649975

[11] Gonçalves, T. S., de Faria, G. L., de Siqueira, R. H. M., and de Lima, M. S. F. "Weldability and mechanical behavior of laser-welded TRIP 750 steel sheets." International Journal of Advanced Manufacturing Technology 107, no. 5-6 (2020): 2807-2815. https://doi.org/10.1007/s00170-020-05223-y

[12] Salleh, M. N. M., Ishak, M., Aiman, M. H., Quazi, M. M., and Hanafi, A. M. "Weld Geometry Investigation on Dissimilar Boron Steel Laser Welded for TWB Application." International Journal of Automotive and Mechanical Engineering 16, no. 4 (2019): 7364-7374. https://doi.org/10.15282/ijame.16.4.2019.12.0546

[13] Khanigi, A. F., Farnia, A., Ardestani, M., and Torkamany, M. J. "Microstructure and mechanical properties of low power pulsed Nd: YAG laser welded S700MC steel." Sādhanā 45, no. 1 (2020): 1-13. https://doi.org/10.1007/s12046-020-1279-6

[14] Chowdhury, S., Nirsanametla, Y., Muralidhar, M., Bag, S., Paul, C. P., and Bindra, K. S. "Identification of modes of welding using parametric studies during ytterbium fiber laser welding." Journal of Manufacturing Processes 57, (2020): 748-761. https://doi.org/10.1016/j.jmapro.2020.07.038

[15] Karlsson, J. and Kaplan, A. F. H. "Analysis of a fibre laser welding case study, utilising a matrix flow chart." Applied Surface Science 257, no. 9 (2011): 4113-4122. https://doi.org/10.1016/j.apsusc.2010.11.185

[16] Lisiecki, A. "Effect of heat input during disk laser bead-on-plate welding of thermomechanically rolled steel on penetration characteristics and porosity formation in the weld metal." Archives of Metallurgy and Materials 61, no. 1 (2016): 93-102. https://doi.org/10.1515/amm-2016-0019 